\title{
A POLÍTICA DE EDUCAÇÃO ESPECIAL DO GOVERNO FHC (1995-2003): UMA OPÇÃO PELA INTEGRAÇÃO
}

Caio Augusto Padilha*

\begin{abstract}
RESUMO
Este artigo tem como objetivo analisar a política de Educação Especial do governo Fernando Henrique Cardoso (1995-2003), de modo a identificar sua contribuição para a construção de um sistema educacional inclusivo. Para tanto, realizou-se uma pesquisa qualitativa, voltada à análise de conteúdo de fontes primárias e secundárias, respectivamente, documentos nacionais e internacionais e produções científicas. A análise dos dados permitiu constatar que o então governo, mesmo tendo atuado na reestruturação do sistema educacional mediante a promoção de amplo conjunto de intervenções no campo legal, preservou o modelo de atuação das administrações anteriores na Educação Especial. Desse modo, mantiveram-se, majoritariamente, a oferta de serviços educacionais apartados às pessoas com deficiência e o investimento em instituições especializadas privadas, prejudicando a inserção de todos os indivíduos no sistema educacional comum.
\end{abstract}

Palavras-chave: Educação. História da educação. Educação especial. Política educacional. Governo Fernando Henrique Cardoso (1995-2003).

\begin{abstract}
THE SPECIAL EDUCATION POLICY OF THE GOVERNMENT FHC (1995-2003): AN OPTION FOR INTEGRATION

This article aims to analyze the Special Education policy from Fernando Henrique Cardoso's government (1995-2003), in order to identify its contribution to the development of an inclusive educational system. For this purpose, a qualitative research was conducted, focused on analysis of primary and secondary sources, being respectively national and international documents and scientific productions. Through data analysis it was possible to state that although being active in the restructuring of the educational system through the promotion of a wide set of interventions in the legal field, the government then maintained the operation model of previous administrations at Special Education. Thus, the provision of detached educational services to disabled people and investment in specialized private institutions has been mostly retained, hindering the insertion of all individuals in the common educational system.
\end{abstract}

Keywords: Education. History of education. Special education. Educational policy. Fernando Henrique Cardoso's government (1995-2003).

* Doutorando em Sociologia pela Universidade Estadual de Campinas (Unicamp). Mestre em Educação pela Faculdade de Educação da Unicamp. Bolsista CAPES. E-mail: padilha.caio@hotmail.com 


\section{RESUMEN}

\section{LA POLÍTICA DE EDUCACIÓN ESPECIAL DEL GOBIERNO DE FHC (1995-2003): UNA OPCIÓN POR LA INTEGRACIÓN}

Este artículo tiene como objetivo analizar la política de Educación Especial del gobierno de Fernando Henrique Cardoso (1995-2003), como una forma de identificar su contribución en la construcción de un sistema educacional inclusivo. Para ello se realizó una pesquisa cualitativa, enfocada en el análisis del contenido de fuentes primarias y secundarias, al igual que documentos nacionales e internacionales así como producciones científicas. El análisis de los datos permitió constatar que dicho gobierno, aún habiendo sido responsable de la reestructuración del sistema educacional mediante la promoción del amplio conjunto de intervenciones en el campo legal, preservó el modelo de actuación de las administraciones anteriores en la Educación Especial. De ese modo se mantuvieron, de forma mayoritaria, la oferta de servicios educacionales apartados a las personas con deficiencia y la inversión en instituciones especializadas privadas, perjudicando la inserción de todos los individuos en el sistema educacional común.

Palabras clave: Educación. Historia de la educación. Educación especial. Política educacional. Gobierno Fernando Henrique Cardoso (1995-2003).

\section{Introdução}

Historicamente, a oferta de serviços educacionais às pessoas com deficiência tem se dado no âmbito da Educação Especial. Multiplicaram-se instituições especializadas e classes especiais destinadas a educar gerações de crianças e adolescentes, de modo apartado da educação comum. Pesquisadores como Romanelli (1978), Ribeiro (2001), Hilsdorf (2005) e Saviani (2010) empreenderam análises históricas da educação brasileira, mas não abordaram diretamente em suas obras o desenvolvimento dessa modalidade educacional, diferentemente de Mazzota (2001), Carvalho (2006), Jannuzzi (2012) e Kassar (1999) que, sob diferentes perspectivas teórico-metodológicas, o fizeram. Conjuntamente a esses trabalhos, este artigo tem como objetivo proceder a uma análise histórica da atuação do governo Fernando Henrique Cardoso (1995-2003) na área da Educação Especial, de modo a identificar o impacto de suas ações para a construção de um sistema educacional inclusivo.

A Educação Inclusiva não somente propõe a inserção de todos os alunos no sistema educacional, como projeta sua transformação radical a partir da modificação de programas de formação docente, das estruturas físicas escolares, dos mecanismos de avaliação da aprendizagem, dos currículos, dos projetos políticos-pedagógicos, das práticas pedagógicas e do cotidiano escolar. Desse processo deve resultar uma escola que problematiza a realidade, as condições materiais e sociais, reconhece e respeita as múltiplas identidades dos seus atores, valoriza o professor, se aproxima da comunidade e tem o aluno como centro do processo educativo ao conceder-lhe autonomia, incentivar sua criticidade e criatividade. Como se pode apreender, essa proposta vai de encontro ao modelo educacional vigorante, pois não admite o funcionamento da educação como meio de normalização dos indivíduos, reprodução da exclusão, do preconceito, da injustiça e da exploração a serviço do capitalismo. Assim, a perspectiva inclusiva produz um sistema educacional em que a escola comum é o ponto de encontro de todos os indivíduos, que ali terão a chance de construir seus próprios percursos de aprendizagem, combinando igualdade de oportunidades com o princípio da diferença (RAWLS, 2002 apud MANTOAN, 2007) e garantindo, por conseguinte, uma igualdade democrática.

Compreende-se que a efetivação do direito de todos à educação, conforme preconiza a Constituição de 1988, e a transformação radical do sistema educacional dependem, necessariamente, de inter- 
venções da sociedade e do Estado. Este atua por intermédio dos governos, que se dedicam a formular programas e ações que devem atender às demandas da sociedade. Dá-se origem às políticas públicas, resultantes de um complexo processo ${ }^{1}$ que sofre interferências de fatores políticos, econômicos, sociais e culturais, mobiliza agentes governamentais e não governamentais, e gera inúmeros embates em suas diferentes etapas. Posto isso, torna-se necessário analisar as atuações governamentais na área educacional ao longo do processo histórico, com vistas a identificar o impacto de suas ações na construção de um sistema educacional inclusivo.

O governo Fernando Henrique Cardoso (19952003), especialmente, teve atuação marcante no campo educacional ao promover uma agenda neoliberal e, em razão disso, reestruturar o sistema, promovendo inúmeras ações, tais como a promulgação da Lei de Diretrizes e Bases (LDB), a criação do Fundo de Manutenção e Desenvolvimento do Ensino Fundamental e de Valorização do Magistério (FUNDEF) e a política de focalização de gastos no ensino fundamental, a elaboração dos Parâmetros Curriculares Nacionais (PCNs), a separação da educação profissional de nível técnico do ensino médio regular, o estímulo à oferta de educação a distância, o incentivo à expansão do ensino superior privado e o lançamento do Plano Nacional de Educação (PNE). No conjunto dessas ações, a Educação Especial, embora não fosse considerada uma área prioritária, também recebeu atenção e foi impactada pela atuação governamental com uma série de ações e programas. Contudo, parte-se da hipótese que essas realizações foram pautadas no princípio da integração, ou seja, da inclusão parcial do alunado com deficiência na educação comum. Sobre o processo, afirma Mantoan (2004, p. 40):

Nas situações de integração escolar, nem todos os alunos com deficiência cabem nas turmas de ensino regular, pois há uma seleção prévia dos que estão aptos à inserção. Para esses casos, são indicados: individualização dos programas escolares, currículos adaptados, avaliações especiais, redução dos objetivos educacionais para compensar as dificuldades de aprender. Em uma palavra, a escola não muda

1 Sobre o processo de elaboração de políticas públicas ver, dentre outros, Höfling (2001), Souza (2006), Mainardes (2006), Frey (2009), Mainardes, Ferreira e Tello (2011). como um todo, mas os alunos têm de mudar para se adaptarem às suas exigências.

Para desenvolver a hipótese, realizou-se, então, uma pesquisa qualitativa de caráter bibliográfico, voltada à análise crítica do conteúdo de fontes primárias (documentos nacionais e internacionais) e secundárias (produções científicas de diferentes naturezas), cujos resultados estão sistematizados neste artigo.

\section{A Educação Especial no primeiro mandato (1995-1999): a promulgação da LDB e o lançamento dos Parâmetros Curriculares Nacionais}

Fernando Henrique Cardoso, ainda enquanto candidato à Presidência da República em 1994, apresentou à sociedade o plano de governo "Mãos à Obra, Brasil". O documento afirmava a necessidade da elaboração de um novo modelo de atuação estatal, que viesse a se adequar às exigências do processo de globalização, combinando a retomada do crescimento econômico com o combate às desigualdades sociais através da intervenção estatal nas áreas da saúde, agricultura, segurança, educação e geração de emprego e renda. Para tanto, previa-se a implantação de um projeto de reforma do Estado, bem como a realização de privatizações, captação de recursos junto aos organismos multilaterais e à iniciativa privada, e a construção de parcerias entre o Estado e a sociedade, sobretudo no que concerne às ações de combate à fome e à miséria e de defesa dos direitos de mulheres, negros, idosos, crianças, adolescentes, indígenas e pessoas com deficiência (CARDOSO, 1994).

Nesse contexto, a educação seria alvo de um extenso conjunto de ações, que objetivavam adequar a formação dos indivíduos ao processo de modernização econômica. Resultam disso os compromissos do então candidato com a reformulação da estrutura administrativa do Ministério da Educação; a universalização do acesso ao ensino fundamental; o estabelecimento de conteúdos curriculares básicos para os diferentes níveis de ensino; o estímulo à descentralização e à participação da sociedade; a criação de mecanismos de avaliação do sistema; a incorporação de novas tecnologias à educação; o estimulo à produtividade no ensino 
superior; a reformulação do ensino médio; e o investimento na expansão da educação profissional (CARDOSO, 1994). A Educação Especial estava longe, portanto, de ser tratada como prioridade na gestão. O plano de governo "Mãos à Obra, Brasil" destinou uma seção específica às pessoas com deficiência. Estavam dispostos ali como objetivos do futuro governo, entre outras coisas, o desenvolvimento de programas de prevenção, a agilização da concessão do benefício de um salário mínimo às pessoas com deficiência e o investimento em acessibilidade, medidas que não implicariam em transformações no sistema educacional, de modo a assegurar o acesso e a permanência desse público nas instituições de ensino.

A ausência da Educação Especial no plano de governo não impediu que Fernando Henrique Cardoso (FHC) e sua equipe intervissem, sobremaneira, na modalidade durante o primeiro mandato. Foi o que se observou a partir da elaboração da LDB e das implementações da Política Nacional de Integração da Pessoa Portadora de Deficiência (1993) e da Política Nacional de Educação Especial (1994). Desse modo, o governo FHC sinalizou seu compromisso com a manutenção do paradigma da integração, que pressupõe a inclusão parcial do alunado com deficiência na escola comum, visto que só são incorporados a esta os indivíduos capazes de se adaptar aos processos educativos (MANTOAN, 1998). Isso posto, paralelamente às escolas comuns, foram preservados os serviços educacionais segregados, mantidos tanto pelo Poder Público quanto pela iniciativa privada, voltados ao atendimento específico de cada deficiência, o que veio a enfraquecer o movimento social pró-inclusão, pois "recrudesceu a disputa entre os grupos de pessoas com diferentes tipos de deficiência pela legitimação de variados projetos educacionais" (PADILHA, 2016, p. 94).

Após uma controversa tramitação no Congresso Nacional, que envolveu, a exemplo do que ocorrera entre os anos 1946 e 1961, confrontos entre correntes que defendiam a educação pública e a educação privada, o governo FHC promulgou, em 20 de dezembro de 1996, a primeira Lei de Diretrizes e Bases da Educação Nacional no período pós-Ditadura Civil-Militar. A versão final da LDB agradou mais aos defensores da iniciativa privada do que aos defensores da escola pública. Apesar de garantir o dever do Estado na oferta da educação escolar pública e na oferta do ensino com base nos princípios da "igualdade de condições para o acesso e permanência na escola" (BRASIL, 1996), a nova lei foi estruturada em torno da flexibilidade, abrindo espaço para o avanço das teses neoliberais no sistema educacional. Desse modo, o Estado poderia se eximir de determinadas responsabilidades sobre os negócios da educação, transferindo suas obrigações para a iniciativa privada, mediante o apelo às empresas e às organizações não governamentais, indo na contramão da Constituição de 1988.

Dessa maneira, durante o governo FHC, ao passo que houve um investimento maciço na universalização do ensino fundamental público, a administração federal valeu-se de seu projeto de reforma do Estado, ${ }^{2}$ que concebia a educação como um serviço não exclusivo à função estatal (BRASIL, 1995a) e incorporava diretrizes favoráveis à desregulamentação, à flexibilização, à descentralização, à privatização e à publicização das aberturas concedidas pela LDB, para encaminhar uma agenda responsável por, dentre outras coisas, expandir o ensino superior privado, introduzir valores neoliberais nos currículos da educação básica e fortalecer parcerias com organizações não governamentais. Posto isso, a Educação Especial continuaria a ser afetada pela forte presença da iniciativa privada, decorrente da histórica ${ }^{3}$ transferência de responsabilidades promovida pelo Estado.

A LDB reservou uma seção específica à Educação Especial, o que, por si só, já significava uma importante conquista, embora seu conteúdo fosse repleto de contradições, prejudiciais à construção de um sistema educacional inclusivo. Apesar de o artigo $3^{\circ}$, inciso I, estabelecer que o ensino deveria ser ministrado com base na "igualdade de condições para o acesso e permanência na escola" (BRASIL, 1996), previa-se, ainda, a oferta da Educação Especial, "preferencialmente na rede regular de ensino, para educandos portadores de necessidades

2 Kassar (2001) desenvolve uma interessante análise sobre a relação entre a reforma do Estado e a Educação Especial.

3 Kassar (1999, 2001), Mazzotta (2001), Jannuzzi (2012) e, mais recentemente, Padilha (2014) abordam a questão em seus trabalhos. 
especiais" (BRASIL, 1996). A problemática utilização dos termos " "preferencialmente", "portador" e "necessidades especiais" foi analisada por Minto (2000, p. 09). Para ele, o termo "preferencialmente" dava abertura ao não cumprimento do artigo, pois “quem 'dá primazia a' já tem arbitrada legalmente a porta da exceção". Já o termo "portador" remetia à ideia de "carregar algo que, por ser 'especial', não cabe no "lugar comum", o que poderia reforçar a "ideia de excluir o diferente ao pressupor uma 'falta' que, talvez, excede em muito a dimensão dela própria" (MINTO, 2000, p. 09). Finalmente, o termo "necessidades especiais" sugeriria "a exigência de cuidados para pessoas "não normais"” (MINTO, 2000, p. 09). Essas interpretações reforçavam, portanto, uma concepção negativa da deficiência, envolta em preconceitos, diametralmente oposta, portanto, a uma conduta democrática, inclusiva.

O parágrafo $1^{\circ}$ do artigo 58 da LDB afirmava a possibilidade de disposição de "serviços de apoio especializado, na escola regular, para atender às peculiaridades da clientela de educação especial" (BRASIL, 1996). Já o parágrafo $2^{\circ}$ determinava a promoção do atendimento educacional em "classes, escolas ou serviços especializados, sempre que, em função das condições específicas dos alunos, não for possível a sua integração nas classes comuns de ensino regular" (BRASIL, 1996). As duas disposições colocavam em xeque a possibilidade de inclusão do alunado nas escolas comuns. A primeira, por estabelecer a disponibilidade de serviços de apoio especializado na escola regular, sem determinar, objetivamente, quais seriam esses serviços e como funcionariam (paralelamente às salas de aulas comuns? De modo complementar, em turno oposto ao das aulas?). A segunda disposição, por sua vez, reforçava o princípio da integração, pois previa o oferecimento de serviços educacionais segregados, que viessem a atuar em "função das condições específicas dos alunos" (BRASIL, 1996), quando estes não fossem considerados capazes de se adequar aos processos educativos da escola comum, ignorando o princípio de que o ensino deveria ser ministrado com

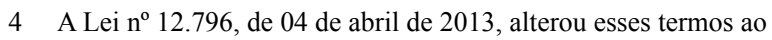
redefinir o público-alvo da Educação Especial. Foi substituída a terminologia "portador de necessidades especiais" por "educandos com deficiência, transtornos globais do desenvolvimento e altas habilidades ou superdotação" (BRASIL, 2013). base na "igualdade de condições para o acesso e permanência na escola" (BRASIL, 1996), como previa a própria lei.

A legislação também incorporou avanços ao estabelecer, ainda no artigo 58 , parágrafo $3^{\circ}$, que a Educação Especial se trataria de um dever constitucional, tendo início "na faixa etária de zero a seis anos, durante a Educação Infantil" (BRASIL, 1996). Mesmo assim, Minto (2000, p. 10) destacou a imprecisão da linguagem, pois "ela pode sugerir que o Estado só ofereça a educação especial em algum momento entre zero e seis anos de idade, aos seis anos (por exemplo), e que estaria, portanto, dentro da faixa etária estabelecida na Lei”.

$\mathrm{O}$ artigo 59, por sua vez, estabeleceu o que os sistemas de ensino deveriam assegurar ao público-alvo da Educação Especial. No inciso I, manteve-se uma lógica oposta à perspectiva inclusiva, prevendo "currículos, métodos, técnicas, recursos educativos e organização específicos [...]" (BRASIL, 1996) para atender o alunado com deficiência. Essa disposição acabaria por isolar esse público, pois, ao assegurar processos de ensino-aprendizagem voltados ao atendimento das necessidades específicas da deficiência, esses alunos inevitavelmente se separariam dos demais. Ademais, numa escola verdadeiramente inclusiva, que respeitasse o direito do indivíduo à diferença, não somente o aluno com deficiência, mas todos os alunos teriam o direito a esses recursos específicos (MANTOAN, 2003). O inciso II estabeleceu o instituto da "terminalidade específica" para os que não pudessem "atingir o nível exigido para a conclusão do ensino fundamental, em virtude de suas deficiências, e aceleração para concluir em menor tempo o programa escolar para os superdotados" (BRASIL, 1996). Tal dispositivo, se veio a facilitar o caminho dos "superdotados", acabou por prejudicar o percurso educativo do alunado com deficiência. Ao abrir o precedente da "terminalidade específica", a legislação não estabeleceu aspectos avaliativos em nenhum item, permitindo que os alunos viessem a concluir o nível fundamental pela idade, sem necessariamente apreender os conhecimentos decorrentes do processo de ensino-aprendizagem dessa etapa. Assim, as pessoas com deficiência poderiam permanecer isoladas em salas 
de aula, alheias ao que estaria sendo ensinado que, mesmo assim, ao final do ciclo, seriam dadas como concluintes do ensino fundamental. Ou seja, o processo de inclusão poderia resultar em fracassos escolares, ocultados pela emissão de certificados.

Ainda no artigo 59, mais especificamente em seu inciso III, estabeleceu-se a necessidade de se formar professores com especialização adequada em nível médio ou superior para o atendimento especializado e professores "capacitados para a integração desses educandos [alunos com deficiência] nas classes comuns" (BRASIL, 1996). Tal disposição abria espaço, ainda, à existência de cursos de formação docente em nível médio, dificultando, portanto, a difusão dos cursos de Pedagogia e das demais licenciaturas, algo que vinha sendo defendido pela comunidade educacional desde as décadas anteriores. Além disso, preservava-se o modelo dicotômico de formação, que implicava no encaminhamento de professores generalistas e especialistas às escolas. Os generalistas pouco ou nada tinham acesso aos conteúdos da Educação Especial, visto que esta era relegada ao segundo plano, ofertada, na maioria das vezes, em disciplinas optativas (BUENO, 1999; SILVA, 2009 apud BUIATTI, 2013). Por sua vez, os especialistas se concentravam no tratamento específico das deficiências, desenvolvendo uma limitada compreensão do fenômeno educacional em sua totalidade, o que prejudicaria a realização de um trabalho articulado com o ensino regular. Desta forma, sem um programa que viesse a congregar aspectos dos dois modelos de formação docente, a construção de um sistema educacional inclusivo estaria severamente prejudicada.

O inciso IV do artigo 59 visava a integração da pessoa com deficiência no mercado de trabalho "mediante articulação com os órgãos oficiais afins, bem como para aqueles que apresentam uma habilidade superior nas áreas artística, intelectual ou psicomotora" (BRASIL, 1996). Tal dispositivo, ainda que pautado em princípios integracionistas, veio a atender aos que reclamavam os movimentos de pessoas com deficiência por intervenções em outros campos, para além das ações na área educacional, com vistas a garantir a efetiva inclusão social das pessoas com deficiência. A geração de emprego era um desses reclamos e a "educação especial para o trabalho" deveria se incumbir de promover a qualificação de milhares de indivíduos que se encontravam alijados do mercado de trabalho. No entanto, a legislação não estabeleceu maiores definições do que seria "educação especial para o trabalho", o que permitiria pressupor certa liberdade aos governos de implementarem diferentes tipos de programas de educação profissional. No caso do governo FHC, a estratégia foi o investimento no Plano Nacional de Educação Profissional (PLANFOR), que incorporava pessoas com deficiência nos cursos de qualificação e requalificação profissional, e nos programas de reabilitação para atividades produtivas (CARDOSO, 1997).

Finalmente, o inciso V do artigo 59 foi de suma importância, pois garantiu o "acesso igualitário aos benefícios dos programas sociais suplementares disponíveis para o respectivo nível do ensino regular" (BRASIL, 1996). Desse modo, aos alunos da Educação Especial se asseguraria o acesso aos programas de alimentação, transporte escolar, livro didático, entre outros, equiparando-os aos da educação comum. Se a inclusão ainda não era o princípio que regia a política educacional, o dispositivo legal ao menos corrigia uma distorção histórica visto que os alunos também eram segregados no tocante à concessão dos benefícios. Num contexto em que ainda prevaleciam serviços apartados de Educação Especial, os recursos eram escassos ${ }^{5}$ e o governo adotava uma estratégia de focalização dos gastos - a universalização do ensino fundamental era a prioridade na agenda -, tal iniciativa garantia ao menos fomento ao alunado.

O artigo 60 determinou que os "órgãos normativos dos sistemas de ensino" deveriam estabelecer os "critérios de caracterização das instituições privadas sem fins lucrativos, especializadas e com atuação exclusiva em educação especial, para fins de apoio técnico e financeiro pelo Poder Público" (BRASIL, 1996). O texto legitimava, portanto, a histórica transferência de responsabilidades do Estado, mediante a transferência de recursos públicos para instituições privadas, ainda que sem fins lucra-

5 A política econômica do governo FHC preservou a Desvinculação de Recursos da União (DRU), que dava poder ao governo federal de desvincular $20 \%$ dos recursos oriundos de impostos e contribuições para utilizá-los em áreas que julgava serem prioritárias para a estabilização econômica, prejudicando, sobremaneira, o financiamento da saúde e da educação. 
tivos, de Educação Especial. Ademais, no parágrafo único do mesmo artigo, o termo "preferencial" viria a aparecer novamente, colocando em xeque a atuação do Estado na "ampliação do atendimento aos educandos com necessidades especiais na própria rede pública regular de ensino, independentemente do apoio às instituições previstas neste artigo"6 (BRASIL, 1996). Assim, por opção do governo, a depender da orientação da política educacional que viesse a ser implementada, a Educação Especial poderia ser ofertada em serviços apartados da educação comum, disponibilizados por instituições privadas.

Posteriormente à promulgação da LDB e em consonância com o lançamento dos Parâmetros Curriculares Nacionais para a Educação Básica, o MEC divulgou, em 1998, o documento "Parâmetros Curriculares Nacionais: adaptações curriculares - estratégias para a educação de alunos com necessidades educacionais especiais". Sua concepção desprezava a capacidade de determinados alunos ao partir do pressuposto de que as necessidades educacionais "especiais" necessariamente estariam associadas a dificuldades maiores que a do restante dos colegas. Desta forma, o próprio texto admitia que a "concepção de especial" estaria "vinculada ao critério de diferença significativa do que se oferece normalmente para a maioria dos alunos da turma no cotidiano da escola" (BRASIL, 1998, p. 27).

Para combater a ineficiência do ensino, que fracassava ao não fazer com que todos os alunos fossem capazes de "aprender a aprender" e, por conseguinte, desenvolver certas competências e habilidades voltadas à futura empregabilidade (SAVIANI, 2010) - como objetivava o projeto educacional neoliberal - é que se propôs um conjunto de adaptações curriculares "relativas" ou "significativas". As primeiras consistiriam em "modificações menores no currículo regular", que poderiam ser produzidas pelos próprios docentes no planejamento e na execução das aulas. Por sua vez, as adaptações "significativas" atenderiam "às necessidades especiais dos alunos, quando estas forem mais acentuadas e não se solucionarem com medidas curriculares menos significativas" (BRASIL, 1998, p. 34) através de alterações nos

6 É necessário destacar que o texto só foi regulamentado anos depois, pelo Decreto $\mathrm{n}^{\circ}$ 6.571, de 17 de setembro de 2008. conteúdos, métodos, atividades, instrumentos de avaliação e até mesmo na organização do tempo pedagógico. Tal flexibilidade, ao invés de promover a inclusão do aluno com deficiência no processo educativo, acabava por alijá-lo no interior da escola. Suas capacidades ficariam subjugadas em nome da deficiência, afinal, todos os componentes já mencionados seriam constituídos não em função de suas potencialidades, mas de suas possíveis limitações. Desse modo, a constituição de um sistema educacional inclusivo não passaria de um ideal distante, pois os alunos que viessem a apresentar "necessidades educativas especiais" jamais participariam do mesmo processo de ensino-aprendizagem que os demais colegas.

Importante iniciativa no campo legal foi a regulamentação do benefício de prestação continuada à pessoa com deficiência, através do Decreto $n^{\circ}$ 1.744, de 08 de dezembro de 1995 (BRASIL, 1995b). Tratava-se, portanto, de mais uma medida governamental em prol da transferência de rendaoutras foram adotadas, como o Bolsa-Escola, por exemplo - num cenário em que a exclusão social da pessoa com deficiência era, ainda, notória. Contudo, o governo não atrelou a concessão do benefício à iniciativa educacional, o que poderia contribuir para ampliar o número de matrículas na educação comum, tal qual ocorrera no Ensino Fundamental, com o Bolsa-Escola, e alavancar o processo de inclusão social.

Não obstante as intervenções no campo legal, o governo Fernando Henrique Cardoso, no decorrer do primeiro mandato, apostou na manutenção da Política Nacional de Integração da Pessoa Portadora de Deficiência e da Política Nacional de Educação Especial. Em razão disso, foram desenvolvidas ações voltadas à remoção de barreiras arquitetônicas, qualificação profissional e reabilitação de pessoas com deficiência - somente em 1996 foram atendidas 437 mil pessoas (CARDOSO, 1997). Nesse mesmo período o MEC distribuiu kits pedagógicos e tecnológicos (estes continham TV, videocassete e antena parabólica) para todas as escolas de Educação Especial do país. Ademais, o governo também investiu na produção de títulos técnicos, que foram encaminhados aos profissionais da modalidade, na produção de conteúdos audiovisuais sobre 
temas relativos às deficiências mental e auditiva, além de "treinar" 40.251 docentes e mais 2.250 "vinculados ao ensino especial", que atendiam, à época, "cerca de 182 mil alunos" (CARDOSO, 1999, p. 63).

Ainda durante o primeiro quatriênio, o MEC investiu na criação de fóruns de Educação Especial nas instituições de ensino superior, organizou Centros de Apoio Pedagógico ao Deficiente Visual em diferentes estados, estimulou a adequação física de escolas e implementou programas de apoio à Educação Especial, visando a "criação de centros especializados na formação de recursos humanos e no desenvolvimento de pesquisa" (CARDOSO, 1999, p. 63), que deveriam beneficiar cerca de 30 instituições de ensino superior. Afora isso, a administração também promoveu ações que, se não interviram diretamente no campo educacional, tiveram efeitos sobre ele. Foram os casos do projeto "Cidade para Todos", executado em parceria com prefeituras, organizações não governamentais e organismos de cooperação internacional, cujo objetivo era o de promover ações de reabilitação profissional para pessoas com deficiência e eliminar barreiras físicas; e do programa "Desporto para Pessoas Portadoras de Deficiência", destinado a não só melhorar a qualidade de vida mas promover a "integração, socialização, recuperação da autoestima e da autoconfiança" (CARDOSO, 1999, p. 139) desses indivíduos e do repasse de 14,6 milhões de reais, entre 1995 e 1998, para a promoção da cidadania e a defesa de direitos através de ações conduzidas por entidades governamentais e não governamentais.

Mesmo não tendo sido uma área prioritária na agenda governamental, a Educação Especial foi alvo de um amplo conjunto de ações, sobretudo no campo legal. Contudo, essas realizações, pautadas no princípio da integração, não modificaram a lógica de funcionamento do sistema educacional. Desse modo, em 1998, último ano do primeiro mandato de Fernando Henrique Cardoso, apesar de o então governo celebrar o aumento de matrículas das pessoas com deficiências nas escolas comuns, a maioria desses alunos ainda estudava em escolas especializadas e classes especiais. Estávamos longe, portanto, da constituição de um sistema educacional inclusivo.

\section{O segundo mandato (1999-2003): o PNE e as Diretrizes Nacionais para a Educação Especial}

Contrariamente ao que ocorreu na primeira campanha eleitoral, o plano de governo da reeleição, "Avança, Brasil", reservou uma seção específica à Educação Especial. Nesta, o então candidato se comprometia com a ampliação da integração nas escolas regulares das "crianças e adolescentes portadores de necessidades especiais" (CARDOSO, 1998, p. 77), o apoio às instituições públicas e privadas de Educação Especial, a promoção de cursos de capacitação de professores para o atendimento especializado, o estímulo ao "acesso a programas de alfabetização, suplência e educação para o trabalho aos alunos maiores de quinze anos" (CARDOSO, 1998, p. 77), o desenvolvimento de materiais que auxiliassem no processo de integração e, finalmente, a aplicação de testes para identificar, sobretudo nas etapas iniciais da escolarização, novos casos de deficiência visual e auditiva.

Para atender aos compromissos de campanha, o governo, no decorrer do segundo mandato, manteve a premissa de implementar tanto a Política Nacional de Educação Especial como a Política Nacional de Integração da Pessoa Portadora de Deficiência, sendo que esta foi reformulada. Além disso, a atuação foi direcionada para a municipalização dos serviços de Educação Especial, a criação dos programas "Desenvolvimento da Educação Especial", "Atenção à Pessoa Portadora de Deficiência" e a manutenção do programa "Cidade para Todos", a constituição do Conselho Nacional dos Direitos da Pessoa com Deficiência (CONADE), a sanção da Lei $\mathrm{n}^{\circ} 10.098$, de 10 de dezembro de 2000 (BRASIL, 2000a), que dispõe sobre a acessibilidade, e a formulação do Plano Nacional de Educação (PNE) e das Diretrizes Nacionais para a Educação Especial na Educação Básica.

A reformulação da Política Nacional de Integração da Pessoa Portadora de Deficiência se deu através do Decreto $\mathrm{n}^{\circ} 3.298$, de 20 de dezembro de 2000 (BRASIL, 2000b). Foram inseridos ${ }^{7}$ cinco

7 Foram inseridos os capítulos "Dos Aspectos Institucionais"; "Da Equiparação de Oportunidades"; Da Política de Capacitação de Profissionais Especializados"; "Da Acessibilidade na Administração Pública Federal"; "Do Sistema Integrado de Informações"; e as seções "Da saúde"; "Do Acesso à Educação"; "Da Habilitação 
novos capítulos e cinco novas seções ao seu texto. Dentre as novas atribuições da Política, ficaram estabelecidas as competências da Coordenadoria Nacional para a Integração da Pessoa Portadora de Deficiência (CORDE), os compromissos com a formação de profissionais que viessem a trabalhar com pessoas com deficiência - no caso do professorado, a formação deveria se dar em nível médio e superior -, os investimentos em pesquisa, desenvolvimento tecnológico e acessibilidade, sobretudo nos espaços públicos, e a criação do Sistema Nacional de Informações, cujas funções seriam as de "criar e manter bases de dados, reunir e difundir informação sobre a situação das pessoas portadoras de deficiência e fomentar a pesquisa e o estudo de todos os aspectos que afetem a vida dessas pessoas" (BRASIL, 2000b).

A Política definiu, ainda, que os serviços de reabilitação integral, formação e qualificação para o trabalho, escolarização no sistema educacional comum ou nas instituições especializadas e de "orientação e promoção individual, familiar e social” (BRASIL, 2000b) deveriam ser ofertados pela administração pública federal. Foi nesse capítulo, "Da Equiparação de Oportunidades", que se definiram as ações para áreas específicas como a saúde (focalização no diagnóstico, na prevenção e na reabilitação), cultura, turismo, desporto, lazer e geração de emprego e renda (criação de cotas para a contratação de pessoas com deficiência nos setores público e privado e implementação de programas de formação e qualificação profissional).

Na seção destinada exclusivamente à educação foram formulados seis artigos (do 24 ao 29). O artigo 24, em seus incisos, estabeleceu as bases da oferta educacional às pessoas com deficiência. Seriam elas: matrícula compulsória dos indivíduos "capazes de se integrar" nas escolas comuns; inclusão da Educação Especial como modalidade de educação escolar, que "permeia transversalmente todos os níveis e modalidades de ensino" (BRASIL, 2000b) mediante sua oferta gratuita e obrigatória na rede pública; inserção de instituições especializadas públicas e privadas no sistema educacional; oferta obrigatória dos serviços educacionais especializa-

e Reabilitação Profissional"; "Do Acesso ao Trabalho"; e "Da Cultura, do Desporto, do Turismo e do Lazer", devidamente incorporadas ao capítulo VII - "Da Equiparação de Oportunidades". dos nas unidades hospitais e congêneres; e garantia de acesso do alunado com deficiência aos benefícios conferidos pelos programas de assistência educacional promovidos pelo aparelho estatal. Além disso, em seus parágrafos, o artigo redefiniu o papel da Educação Especial como modalidade oferecida "preferencialmente" na escola regular para o "educando com necessidades educacionais especiais, entre eles o portador de deficiência" (BRASIL, 2000b) a partir da Educação Infantil, devendo se constituir como um processo "flexível, dinâmico e individualizado" a ser conduzido por uma equipe multidisciplinar (BRASIL, 2000b). Outrossim, determinou-se também, que a construção e reforma dos estabelecimentos de ensino deveria se dar em conformidade com as normas de acessibilidade produzidas pela Associação Brasileira de Normas Técnicas (ABNT).

Os artigos 25 e 26 estabeleceram, respectivamente, a oferta da Educação Especial nas instituições de ensino público ou privado, "de forma transitória ou permanente mediante programas de apoio para o aluno que está integrado no sistema regular de ensino" ou em escolas especiais quando a educação comum não satisfizesse as "necessidades educativas ou sociais do aluno ou quando necessário ao bem-estar do educando" (BRASIL, 2000b). Os artigos 27 e 28 dispunham, por sua vez, sobre o acesso ao ensino superior e à educação profissional. Às instituições de educação superior se estabelecia o dever de ofertar provas adaptadas, "conteúdos, itens ou disciplinas" relacionados às pessoas com deficiência (BRASIL, 2000b) e o acesso à educação profissional, como parte do processo de inserção produtiva preconizado pelo MEC, "nos níveis básico, técnico e tecnológico, em escola regular, em instituições especializadas e nos ambientes de trabalho" (BRASIL, 2000b) deveria se dar em cursos profissionais que condicionariam a matrícula à capacidade de aproveitamento do aluno e não ao seu nível de escolaridade. Finalmente, no artigo 29, a Política dispôs sobre a oferta, através das instituições de educação profissional, de "serviços de apoio especializado para atender as peculiaridades da pessoa portadora de deficiência" (BRASIL, 2000b) por meio da adaptação de recursos pedagógicos e físicos, e da capacitação de recursos humanos. 
A Política, mesmo reformulada, apenas referendou as disposições da Política Nacional de Educação Especial e da própria LDB. Apesar de estabelecer como compromissos o investimento em pesquisa e desenvolvimento tecnológico, a inserção da pessoa com deficiência no mercado de trabalho e definir ações para as áreas de saúde, cultura, turismo, lazer e desporto, que, de diferentes formas, contribuiriam para a construção de uma sociedade inclusiva, não se pode afirmar que o documento manteve a mesma orientação no campo educacional. Embora reafirmasse a necessidade de adequação dos prédios escolares às normas de acessibilidade e a garantia de acesso do alunado com deficiência aos benefícios conferidos pelos programas de assistência educacional promovidos pelo aparelho estatal, importantes avanços, o que se pode apreender da Política é o seu compromisso com a manutenção do princípio da integração. A utilização da controversa terminologia "necessidades educacionais especiais", a previsão de inclusão somente dos indivíduos "capazes de se integrar" à educação comum, a possibilidade de realização de adaptações curriculares em diferentes etapas do processo educacional e a permanência da oferta de classes especiais e instituições especializadas públicas e privadas só corroborariam isso.

A municipalização da Educação Especial se adequou à estratégia de descentralização dos serviços educacionais adotada pelo MEC durante os oito anos de mandato de FHC. Com o auxílio do FUNDEF - 5\% dos recursos seriam destinados à Educação Especial - imaginava-se ampliar o número de matrículas ao transferir a oferta do atendimento educacional às pessoas com deficiência dos estados para os municípios. Contudo, a estratégia não foi bem-sucedida, pois não foram asseguradas as condições necessárias, previstas no documento "Expansão e Melhoria da Educação Especial nos Municípios Brasileiros" "para que estes se adequas-

8 Eram sugestões do MEC para os municípios: a conscientização da sociedade e, mais especificamente, da comunidade escolar; a criação de setores responsáveis pela Educação Especial dentro das Secretarias Municipais de Educação; a sistematização da capacitação de recursos humanos para atender as pessoas com deficiência; o levantamento da demanda de público para o atendimento educacional especializado; o mapeamento da rede física, mobiliário e equipamento das instituições escolares e o eventual provimento desses recursos caso não houvesse; a normatização do atendimento educacional pelos Conselhos Municipais de sem às novas responsabilidades. Por conseguinte, persistiram as disparidades regionais na oferta dos serviços educacionais especializados - o Nordeste, por exemplo, não oferecia Educação Especial em $78,3 \%$ dos municípios e mesmo em regiões mais desenvolvidas economicamente como o Sul, o atendimento não alcançava $41,9 \%$ dos municípios (BRASIL, 2001b).

O programa "Desenvolvimento da Educação Especial" destinava-se a "ampliar e melhorar a oferta de oportunidades de atendimento aos portadores de necessidades educativas especiais" (CARDOSO, 2000, p. 53) através da ação conjunta entre os diferentes órgãos do governo, instituições internacionais e representantes da sociedade. Tratava-se de uma iniciativa voltada à operacionalização das diretrizes da Política Nacional de Educação Especial então vigente. Desse modo, o MEC manteve a estratégia de distribuição de kits pedagógicos e tecnológicos; produziu conteúdos educativos para a TV Escola; investiu na capacitação de professores da rede pública e das organizações não governamentais por intermédio de cursos a distância de curta duração, que preparavam para o atendimento a uma deficiência específica; e desenvolveu o Projeto de Informática na Educação Especial (PROINESP), responsável por implantar, nas escolas especiais, laboratórios de informática e o "Curso de Capacitação de Multiplicadores em Informática na Educação". Contudo, a ação mais importante foi a incorporação da Educação Especial aos grandes programas de assistência do MEC - "Saúde do Escolar", "Transporte Escolar", "Dinheiro Direto na Escola", "Livro Didático" -, tal qual estabelecia a LDB. Por sua vez, o programa "Atenção à Pessoa Portadora de Deficiência", embora não tenha se dado no âmbito do Ministério da Educação e, sim, no da Secretaria de Estado da Assistência Social, foi relevante, pois contemplava "serviços assistenciais nas modalidades de estimulação precoce, prevenção de deficiências, habilitação e reabilitação, trabalho e vida independente, bem como [desenvolvia] projetos de revitalização da rede prestadora de serviços" (CARDOSO, 2000, p. 97).

Educação; e, finalmente, a solicitação de apoio técnico-financeiro para os estados e a União (BRASIL, 1994). 
A criação, em 2002, do CONADE, ${ }^{9}$ no âmbito do Ministério da Justiça, foi uma ação de suma importância, pois tal conselho, composto tanto de membros do governo quanto de representantes de entidades da sociedade civil organizada, se voltaria ao "planejamento, acompanhamento e avaliação das políticas públicas voltadas para os portadores de deficiência" (CARDOSO, 2000, p. 112). Assim sendo, o novo órgão atenderia, finalmente, aos reclamos dos movimentos sociais de pessoas com deficiência que, ao menos desde os anos 1970, lutavam pela conquista do direito de participação nos processos de elaboração de políticas públicas a elas destinadas.

Em consonância com a manutenção do programa "Cidade para Todos", que promovia ações voltadas à promoção da acessibilidade, foi elaborada, no ano 2000, a Lei n ${ }^{\circ} 10.098$, que estabeleceu "normais gerais e critérios básicos para a promoção da acessibilidade das pessoas portadores de deficiência ou com mobilidade reduzida" através da "supressão de barreiras e de obstáculos" (BRASIL, 2000) nos espaços públicos e privados. A legislação, dentre outras coisas, trouxe à tona conceitos como o de acessibilidade ${ }^{10}$ e barreiras, ${ }^{11}$ impôs determinações para os processos de urbanização, planejamento e localização do mobiliário urbano, adequação dos veículos de transporte coletivo, sistemas de comunicação e sinalização e edifícios públicos, privados ou de uso coletivo. Todavia, a nova legislação não teve o impacto inicial almejado, pois só seria regulamentada em 2004, já no governo de Luiz Inácio Lula da Silva.

As instituições especializadas públicas, casos do Instituto Benjamin Constant (IBC) e do Instituto Nacional de Educação de Surdos (INES), também receberam especial atenção governamental. Havia o intento de transformá-los em "centros de referência nacional, direcionados para a pesquisa e de-

9 Para uma visão mais ampla das atribuições do CONADE, ver Teixeira (2010).

10 De acordo com a Lei, acessibilidade seria a "possibilidade e condição de alcance para utilização, com segurança e autonomia, dos espaços, mobiliários e equipamentos urbanos, das edificações, dos transportes e dos sistemas e meios de comunicação, por pessoa portadora de deficiência ou com mobilidade reduzida" (BRASIL, 2000).

11 Barreiras, por sua vez, se consistiriam em "qualquer entrave ou obstáculo que limite ou impeça o acesso, a liberdade de movimento e a circulação com segurança das pessoas" (BRASIL, 2000). senvolvimento de tecnologia" (CARDOSO, 2000, p. 53). Essa atuação levou o IBC a desenvolver o software "Braille Fácil", voltado à impressão de textos em Braille, e a adaptar livros didáticos a esse sistema de leitura. O INES, por sua vez, veio a atuar na formação de recursos humanos, capacitando profissionais - presencialmente e a distância - para o atendimento à pessoa com deficiência auditiva.

A elaboração do Plano Nacional de Educação (PNE) foi, possivelmente, a mais importante realização do segundo governo $\mathrm{FHC}$, pois se tratava de um documento definidor das diretrizes e ações que deveriam ser encampadas pelo aparelho estatal no campo educacional num período de dez anos. Contudo, assim como ocorrera com a LDB, a formulação do PNE se deu de maneira controversa. Novamente, os anseios de parcelas significativas da comunidade educacional, reunidas no Fórum Nacional em Defesa da Escola Pública, foram ignorados pelo governo. Assim, o projeto inicial, encaminhado pela sociedade, foi majoritariamente vetado $^{12}$ pelo governo em detrimento da reiteração da política que já vinha sendo conduzida pelo Ministério da Educação, determinada a comprimir gastos públicos e transferir responsabilidades, "especialmente de investimento e manutenção do ensino" para os entes federativos e a iniciativa privada, "ficando a União com as atribuições de controle, avaliação, direção e, eventualmente, apoio técnico e financeiro de caráter subsidiário e complementar" (SAVIANI, 2002, p. 82).

À Educação Especial, o PNE reservou uma seção exclusiva, composta por três subseções: diagnóstico, diretrizes e objetivos e metas. Na primeira, o governo reconhecia a gravidade dos problemas que envolviam a modalidade ao afirmar que "inexistência, insuficiência, inadequação e precariedades podem ser constatadas em muitos centros de

12 Trópia (2011, p. 22) faz um levantamento dos vetos governamentais ao projeto inicial: "Foram vetadas metas da educação infantil vinculadas ao programa de renda mínima; a meta de $40 \%$ da escolaridade para o ensino superior; de vinculação de $75 \%$ dos recursos da União voltados para manutenção e desenvolvimento do ensino da rede federal; aumento do crédito educativo a $30 \%$ dos alunos da rede privada; plano de carreira para os funcionários das universidades federais; ampliação do financiamento para ciência e tecnologia; e finalmente os vetos mais importantes: o veto aos $7 \%$ do PIB, no mínimo, com educação e à exclusão do pagamento de aposentados e pensionistas do ensino superior público das despesas consideradas como manutenção e desenvolvimento do ensino". 
atendimento a essa clientela" (BRASIL, 2001b). De fato, o cenário era alarmante: em 1998, a Educação Especial não era ofertada por $60 \%$ dos municípios brasileiros e $62 \%$ do atendimento às pessoas com deficiência se dava em escolas especializadas, sobretudo em instituições privadas $(53,1 \%$ das matrículas ali se concentravam), o que, de acordo com o texto do PNE, refletia a "necessidade de um compromisso maior da escola comum com o atendimento do aluno especial" (BRASIL, 2001b).

Na segunda subseção, o PNE estabeleceu como diretriz a formulação de uma política de acesso à educação que viesse a abranger os âmbitos social e educacional. Isso implicava em reconhecer o direito das pessoas com deficiência de "estarem integrados na sociedade o mais plenamente possível" (BRASIL, 2001b). Para tanto, se tornaria necessário adequar o espaço escolar, equipamentos e materiais pedagógicos e qualificar os profissionais da educação para o processo de inclusão, de modo a viabilizar a existência de um projeto de escola "integradora, inclusiva, aberta à diversidade dos alunos" (BRASIL, 2001b). Todavia, a estratégia adotada no plano para solucionar esses problemas não era uma novidade: foram estabelecidas diretrizes secundárias como o incentivo à estimulação precoce; a articulação entre saúde, educação e assistência; a garantia de oferta de vagas em todos os níveis de ensino para as pessoas com deficiência; a celebração de convênios com os municípios; e a manutenção do apoio à iniciativa privada. $\mathrm{O}$ plano, portanto, ia na contramão de uma concepção inclusiva de escola. Propunha-se uma escola integradora, o que já era ofertado, visto que só os “mais capazes de se adaptar" continuariam a ser inseridos na educação comum. Afora isso, preservava-se a aposta na transferência de responsabilidades para os municípios, sem a necessária salvaguarda da União para a implementação dos serviços, e de recursos para a iniciativa privada, que se incumbiria de conservar e expandir suas instituições especializadas.

Mesmo tendo incorporado a perspectiva da integração, a possível execução do PNE provocaria mudanças no cenário da Educação Especial, pois havia um compromisso estatal melhor delineado com a modalidade. A seção "objetivos e metas" continha ações que o governo federal deveria promover no prazo de 10 anos. Dentre elas, destacam-se a gene- ralização, em 5 anos, da formação de professores para o atendimento educacional especializado; a ampliação da oferta de estimulação precoce; o redimensionamento e o incremento às classes especiais e salas de recursos - ao invés da eliminação das primeiras; a generalização do atendimento na educação infantil e no ensino fundamental - não se falava, contudo, em ensino médio, muito menos em ensino superior; e a criação de centros de atendimento especializado às pessoas com "severas dificuldades de desenvolvimento" (BRASIL, 2001b), meta que fortaleceria o papel da Coordenadoria Nacional para a Integração da Pessoa Portadora de Deficiência (CORDE). Ainda, visava-se a implantação do ensino de LIBRAS; a adequação física das escolas e a construção de novos prédios; o incentivo à pesquisa em Educação Especial; o estímulo à educação para o trabalho - sem, no entanto, que se especificasse em quais bases esse processo de formação se daria; e, finalmente, o aumento do repasse de recursos à modalidade, "a fim de atingir, em dez anos, o mínimo equivalente a 5\% dos recursos vinculados à manutenção e desenvolvimento do ensino" (BRASIL, 2001b). Além desses objetivos e metas, generalistas, é oportuno destacar as que se destinavam à iniciativa privada: a definição e implantação de indicadores de qualidade para o funcionamento de instituições particulares (as públicas também seriam alvo desses mecanismos) e a promessa de "assegurar a continuidade do apoio técnico e financeiro às instituições privadas sem fim lucrativo com atuação exclusiva em educação especial, que realizem atendimento de qualidade [...]" (BRASIL, 2001b). Esses compromissos, entretanto, não foram cumpridos pelo governo FHC, visto que o PNE foi aprovado somente no final do segundo mandato, em 2001, cabendo ao próximo presidente, Luiz Inácio Lula da Silva, o dever de implementá-lo.

$\mathrm{O}$ apoio do governo à iniciativa privada no âmbito da Educação Especial foi flagrante. Mediante a celebração de acordos de cooperação técnica e financeira com o MEC, as instituições especializadas privadas continuaram a substituir o Poder Público no cumprimento de suas funções. Apesar de o governo declarar a intenção de ampliar a oferta de vagas nas escolas comuns públicas, o que se viu foi a preservação da oferta majoritária de serviços 
de Educação Especial privados, visto que, entre 1998 e 2002, a matrícula de alunos em instituições especializadas não estatais oscilou negativamente apenas $0,1 \%$ - de $46,8 \%$ para $46,7 \%$ (BRASIL, 2008), fato que fortalecia seu poder político e lhe assegurava condições suficientes para inibir ações estatais pró-inclusão, já que estas fatalmente prejudicariam seus interesses de conservação do oferecimento de serviços educacionais apartados da educação comum às pessoas com deficiência.

Em 2001, o governo brasileiro adotou, através do Decreto $\mathrm{n}^{\circ} 3.956$, os princípios da Convenção da Guatemala, realizada dois anos antes. Tal iniciativa deu início a uma guinada na atuação estatal em favor da inclusão. A Convenção anunciava que os Estados-parte deveriam tomar "medidas de caráter legislativo, social, educacional, trabalhista, ou de qualquer outra natureza" para eliminar a discriminação das pessoas com deficiência e "proporcionar sua plena integração à sociedade" (ORGANIZAÇÃO DOS ESTADOS AMERICANOS, 1999). Em razão disso, os governos deveriam promover acessibilidade, conscientizar a população e conceder prioridade à detecção e intervenção precoce, ao tratamento, à reabilitação, à educação, à formação ocupacional e à prestação de serviços completos para "garantir o melhor nível de independência e qualidade de vida para as pessoas portadoras de deficiência" (ORGANIZAÇÃO DOS ESTADOS AMERICANOS, 1999).

Em decorrência dessas novas mobilizações dos organismos multilaterais e, sobretudo, do fortalecimento dos movimentos pró-inclusão, o MEC, já no apagar das luzes do governo Fernando Henrique Cardoso, lançou as Diretrizes Nacionais para a Educação Especial, através da Resolução $\mathrm{CNE} / \mathrm{CEB} \mathrm{n}^{\mathrm{o}} 2$, de 11 de setembro de 2001. No livro elaborado para divulgá-las, o então ministro da Educação Paulo Renato Costa Souza, além de reconhecer que o "diferente" havia sido colocado à margem da educação durante muito tempo, fazendo com que os alunos com deficiência, especialmente, fossem atendidos separadamente ou simplesmente excluídos do processo educativo, "com base em padrões de normalidade", afirmou que, "no horizonte da educação inclusiva” (BRASIL, 2001a, p. 05) era necessário mudar a maneira de enxergar esses indivíduos. Ou seja, ao invés de pensa-los como “a origem de um problema", exigindo o "ajustamento a padrões de normalidade para aprender com os demais, coloca[va]-se para os sistemas de ensino e as escolas o desafio de construir coletivamente as condições para atender bem à diversidade de seus alunos (BRASIL, 2001a, p. 06). Desse modo, o discurso oficial adotava pela primeira vez o termo "educação inclusiva" para pautar as futuras ações governamentais, o que consistia um avanço importante, ainda que, na prática, as políticas públicas continuassem a ser elaboradas e implementadas sob o princípio da integração.

As Diretrizes ${ }^{13}$ foram lançadas, entremeadas de contradições. À medida que se avançava ao dispor que os "sistemas de ensino [deveriam] matricular todos os alunos"; assegurar o atendimento educacional em escolas comuns; promover a acessibilidade - "mediante a eliminação de barreiras arquitetônicas urbanísticas" e a "utilização de linguagens e códigos aplicáveis, como o sistema Braille e a língua de sinais"; e ainda dispusesse sobre a implantação de salas de recursos, "nas quais o professor especializado em educação especial realize a complementação ou suplementação curricular, utilizando procedimentos, equipamentos e materiais específicos" (BRASIL, 2001a), foram estabelecidos dispositivos que, contraditoriamente ao que discursara o ministro, reforçavam o princípio da integração. Nessa direção, garantiram-se a manutenção das flexibilizações e adaptações curriculares e da terminalidade específica; a prerrogativa das escolas criarem classes especiais "para atendimento, em caráter transitório, a alunos que apresentem dificuldades acentuadas de aprendizagem [...]" (BRASIL, 2001a); ${ }^{14}$ o direito daqueles alunos que viessem a requerer "atenção individualizada nas atividades da vida autônoma e social" (BRASIL, 2001a) ao atendimento, articulado aos serviços de saúde, trabalho e assistência social, em escolas especiais públicas e privadas; e se sugeria um modelo de formação docente que contemplasse

13 Para uma melhor análise dos artigos das Diretrizes, ver Kassar (2002).

14 Nesses casos, o retorno às escolas comuns só se daria após as famílias decidirem, em conjunto com as equipes pedagógicas (BRASIL, 2001a), algo incomum, pois, segundo Mantoan (2004, p. 40), "os alunos que migram das escolas comuns para serviços de educação especial muito raramente se deslocam para os menos segregados e dificilmente retornam às salas de aula do ensino regular". 
professores capacitados para classes comuns com "alunos que apresentam necessidades especiais" $15 \mathrm{e}$ professores especializados em Educação Especial. Desse modo, valendo-se ainda de terminologias inadequadas - vide a utilização do termo "necessidades educacionais especiais" -, as Diretrizes Nacionais para a Educação Especial possibilitaram que instituições especializadas e classes especiais públicas e privadas fossem mantidas, processos de ensino-aprendizagem continuassem a ser distintos em razão da deficiência e professores se vissem distantes de um modelo de formação ${ }^{16}$ que articulasse os conhecimentos gerais para o exercício da docência e os conhecimentos específicos da modalidade tal qual pressupõe a educação inclusiva.

As Diretrizes Nacionais para a Educação Especial na Educação Básica foram o último grande ato do governo FHC no segundo mandato, no que diz respeito à Educação Especial. O que se viu, no quatriênio 1999-2003, foi a preservação do mesmo modelo de atuação implantado no decorrer do primeiro mandato, ainda que alguns avanços tímidos tenham sido realizados, sobretudo no campo discursivo, em prol da educação inclusiva. Desse modo, entre 1998 e 2002, houve aumento de matrículas de alunos com deficiência no sistema educacional - o número evoluiu de 337.326 para 448.601 (BRASIL, 2008) -, mas prevalecia ainda a oferta majoritária de serviços educacionais especializados, apartados da educação comum. Nestas estavam matriculados 337.897 alunos em 2002, enquanto nas escolas regulares estavam inseridos, no mesmo ano, 110.704. Eram números que somente reforçavam, portanto, a manutenção do princípio da integração.

15 Kassar (2002) aponta o uso indevido, novamente, em um documento governamental do termo "necessidades educativas especiais", o que poderia pressupor que crianças com dificuldade acentuada de aprendizagem poderiam ser consideradas parte desse público. Segundo a pesquisadora, grande parte das crianças que frequentavam classes especiais e eram reconhecidas como possuidoras de dificuldade de aprendizagem, desde o fim dos anos 1970, na realidade, sofriam com os problemas de "ensinagem". Desse modo, o encaminhamento dessas crianças para as instituições especializadas consistiria numa estratégia equivocada, que só viria a corroborar que a escola não viesse a modificar suas práticas de ensino, ocultando os casos de "fracasso escolar" sob o rótulo das "necessidades educacionais especiais".

16 Bueno (1999) estabelece uma discussão acerca da formação docente na perspectiva inclusiva, destacando a necessidade de romper com o tradicional modelo dicotomizado, que se destinou a formar professores generalistas e especialistas.

\section{Considerações finais}

Enquanto estiveram à frente do poder, Fernando Henrique Cardoso e sua equipe preservaram o modelo de atuação adotado pelos antecessores na Educação Especial. Desse modo, o princípio da integração, que respaldou, durante décadas, a existência de instituições especializadas e classes especiais destinadas ao atendimento educacional de pessoas com deficiência, continuou a pautar a política de Educação Especial. Isso não impediu que o governo avançasse em alguns pontos na construção de um sistema educacional inclusivo. Foram lançados programas de acessibilidade, a criação do CONADE veio a assegurar espaço às pessoas com deficiência no processo de elaboração das políticas públicas e a Educação Especial foi incorporada aos programas de assistência educacional, igualando os alunos da modalidade aos da educação comum na concessão desses auxílios. No entanto, medidas de incentivo à municipalização dos serviços de Educação Especial sem o necessário apoio da União para que se assegurassem as condições necessárias para tal, a implementação de adaptações curriculares e o instituto da terminalidade específica, a manutenção de programas de formação docente dicotomizados, os investimentos escassos na modalidade e o apoio à atuação de instituições especializadas públicas e privadas foram algumas das ações que só vieram a reforçar a inclusão parcial das pessoas com deficiência na educação comum em detrimento da necessária inclusão de todos no sistema.

O governo, embora intervisse no campo legal, não lançou as bases para a elaboração de uma política educacional que viabilizasse as necessárias transformações no sistema com vistas a torná-lo inclusivo. A LDB e o PNE, mesmo concedendo um novo espaço institucional à Educação Especial, reafirmaram antigas concepções de integração em disposições genéricas e por vezes contraditórias. A Política Nacional de Educação Especial foi implementada, assim como a Política Nacional para Integração da Pessoa Portadora de Deficiência, que foi, inclusive, reformulada e ampliada. Nem mesmo a mudança de discurso do ministro e a elaboração das Diretrizes Nacionais para a Educação Especial na Educação Básica, já no apagar das luzes do mandato, modificariam o paradigma vigente. Posto 
isso, o Estado brasileiro continuaria a promover a exclusão de milhares de pessoas com deficiência do sistema educacional comum, atendendo apenas os que fossem considerados "capazes" de se integrar. O País continuaria distante, portanto, de oferecer uma educação inclusiva.

\section{REFERÊNCIAS}

BRASIL. Secretaria de Educação Especial. Expansão e melhoria da Educação Especial nos municípios brasileiros. Brasília, DF: MEC/SEESP, 1994.

Ministério da Administração Federal e Reforma do Estado (MARE). Plano diretor da reforma do aparelho do Estado. Brasília, DF, 1995a.

Presidência da República. Casa Civil. Decreto n 1.744, de 08 de dezembro de 1995. Regulamenta o be-

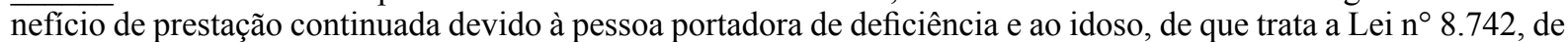
7 de dezembro de 1993, e dá outras providências. Brasília, DF, 1995b. Disponível em: <http://www.planalto.gov. br/ccivil_03/decreto/antigos/d1744.htm>. Acesso em: 29 out. 2017.

Presidência da República. Casa Civil. Lei no 9.394, de 20 de dezembro de 1996. Estabelece as diretrizes e bases da educação nacional. Brasília, DF, 1996. Disponível em: <http://www.planalto.gov.br/ccivil_03/leis/19394. htm>. Acesso em: 30 out. 2017.

. Ministério da Educação. Secretaria do Ensino Fundamental. Secretaria de Educação Especial. Parâmetros Curriculares Nacionais. Adaptações Curriculares. Estratégias para a Educação de Alunos com Necessidades Educacionais Especiais. Brasília, DF, 1998.

Lei $\mathrm{n}^{\circ} 10.098$, de 19 de dezembro de 2000. Estabelece normas gerais e critérios básicos para a promoção da acessibilidade das pessoas portadoras de deficiência ou com mobilidade reduzida, e dá outras providências. Brasília, DF, 2000. Disponível em: <http://www.planalto.gov.br/ccivil_03/leis/110098.htm>. Acesso em: 30 out. 2017.

Presidência da República. Casa Civil. Decreto no 3.298, de 20 de dezembro de 2000. Regulamenta as Leis nos 10.048 , de 8 de novembro de 2000, que dá prioridade de atendimento às pessoas que especifica, e 10.098 , de 19 de dezembro de 2000, que estabelece normas gerais e critérios básicos para a promoção da acessibilidade das pessoas portadoras de deficiência ou com mobilidade reduzida, e dá outras providências. Brasília, DF, 2000. Disponível em: <http://www.planalto.gov.br/ccivil_03/_ato2004-2006/2004/decreto/d5296.htm>. Acesso em: 28 out. 2017.

Presidência da República. Casa Civil. Lei no 10.172, de 09 de janeiro de 2001. Aprova o Plano Nacional de Educação e dá outras providências. Brasília, DF, 2001b. Disponível em: <http://www.planalto.gov.br/ccivil_03/ leis/leis_2001/110172.htm>. Acesso em: 29 out. 2017. $\overline{\mathrm{DF}, 2001 \mathrm{a} .}$

Ministério da Educação. Diretrizes Nacionais para Educação Especial na Educação Básica. Brasília,

Presidência da República. Casa Civil. Lei n⿳0 12.796, de 04 de abril de 2013. Altera a Lei no 9.394, de 20 de dezembro de 1996, que estabelece as diretrizes e bases da educação nacional, para dispor sobre a formação dos profissionais da educação e dar outras providências. Brasília, DF, 2013. Disponível em: <http://www.planalto.gov. br/ccivil_03/_ato2011-2014/2013/lei/112796.htm>. Acesso em: 17 out. 2017.

. Ministério da Educação. Política Nacional de Educação Especial na Perspectiva da Educação Inclusiva. Brasília, DF, 2008. Disponível em: $<$ http://portal.mec.gov.br/arquivos/pdf/politicaeducespecial.pdf $>$. Acesso em: 30 out. 2017.

BUENO, José Geraldo Silveira. Crianças com necessidades educativas especiais, política educacional e a formação de professores: generalistas ou especialistas. Revista Brasileira de Educação Especial, v. 3, n. 5, p. 7-25, 1999.

BUIATTI, Viviane Prado. Atendimento educacional especializado: dimensão política, formação docente e concepções dos profissionais. 2013. 324f. Tese (Doutorado em Educação) - Universidade Federal de Uberlândia (UFU), Uberlândia, MG, 2013.

CARDOSO, Fernando Henrique. Mãos à obra, Brasil: proposta de governo. Brasília, DF: SDE, 1994.

. Presidência da República do Brasil. Mensagem ao Congresso Nacional. Brasília, DF, 1997. 
Avança Brasil: proposta de governo. Brasília, DF, 1998.

Presidência da República do Brasil. Mensagem ao Congresso Nacional. Brasília, DF, 1999.

Presidência da República do Brasil. Mensagem ao Congresso Nacional. Brasília, DF, 2000.

CARVALHO, Rosita Edler. Educação inclusiva: com os pingos nos "is". 4. ed. Porto Alegre: Meditação, 2006.

FREY, Klaus. Políticas públicas: um debate conceitual e reflexões referentes à prática da análise de políticas públicas no Brasil. Planejamento e Políticas Públicas, Rio de Janeiro, n. 21, p. 211-259, 2009.

HILSDORF, Maria Lúcia S. História da educação brasileira: leituras. São Paulo: Pioneira Thomson Learning, 2005.

HÖFLING, Eloísa de Mattos. Estado e políticas (públicas) sociais. Cadernos CEDES, Campinas, SP, v. 21, n. 55, p. 30-41, 2001.

JANNUZZI, Gilberta S. de M. A educação do deficiente no Brasil: dos primórdios ao início do século XXI. 3. ed. Campinas, SP: Autores Associados, 2012.

KASSAR, Mônica de C. M. Reforma do estado e educação especial: preliminares para uma análise. Revista de Educação, Campinas, SP, v. 11, n. 1, p. 24-34, 2001.

Deficiência múltipla e educação no Brasil: discurso e silêncio na história de sujeitos. Campinas, SP: Autores Associados, 1999.

Políticas nacionais de educação inclusiva - discussão crítica da Resolução $n^{\circ}$ 02/2001. Ponto de Vista: revista de educação e processos inclusivos, n. 3-4, p. 13-25, 2002.

MAINARDES, Jefferson. Abordagem do ciclo de políticas: uma contribuição para a análise de políticas educacionais. Educação e Sociedade, Campinas, SP, v. 27, n. 94, p. 47-69, 2006.

MAINARDES, Jefferson; FERREIRA, M. dos S.; TELLO, César. Análise de políticas: fundamentos e principais debates teórico-metodológicos. In: BALL, Stephen; MAINARDES, Jefferson (Org.). Políticas educacionais: questões e dilemas. São Paulo: Cortez, 2011. p. 143-172.

MANTOAN, Maria Teresa. Igualdade e diferenças na escola - como andar no fio da navalha. Revista Inter Ação, v. 31, n. 2, p. 185-196, ago. 2007.

O direito à diferença nas escolas - questões sobre a inclusão escolar de pessoas com e sem deficiências. Revista Educação Especial, n. 23, p. 17-23, 2004.

MANTOAN, M. T. E. Integração X Inclusão - educação para todos. Pátio - Revista Pedagógica, Porto Alegre, ano 2, n. 5, p. 48-51, maio/jul. 1998.

Inclusão escolar: o que é? Por quê? Como Fazer? São Paulo: Moderna, 2003.

MAZZOTTA, Marcos J. S. Educação especial no Brasil. História e políticas públicas. 3. ed. São Paulo: Cortez, 2001.

MINTO, C. A. Educação especial: da LDB aos Planos Nacionais de Educação - do MEC e Proposta da Sociedade Brasileira. Revista Brasileira de Educação Especial, Marília, SP, v. 1, n. 1, p. 1-26, 2000.

ORGANIZAÇÃO DOS ESTADOS AMERICANOS (OEA). Convenção Interamericana para a Eliminação de Todas as Formas de Discriminação contra as Pessoas Portadoras de Deficiência. Guatemala, 1999.

PADILHA, Caio Augusto Toledo. Educação e inclusão no Brasil (1985-2010). 2014. 391f. Dissertação (Mestrado em Educação) - Faculdade de Educação da Universidade Estadual de Campinas (Unicamp), Campinas, SP, 2014.

. A política educacional do governo Itamar Franco (1992-1995) e a questão da inclusão. Revista Espaço Acadêmico, ano 16, n. 180, p. 82-97, 2016.

RIBEIRO, Maria Luisa Santos. História da educação brasileira: a organização escolar. Campinas, SP: Autores Associados, 2001.

ROMANELLI, Otaíza Oliveira. História da educação no Brasil (1930-1973). Petrópolis, RJ: Vozes, 1978.

SAVIANI, Dermeval. História das ideias pedagógicas no Brasil. 3. ed. Campinas, SP: Autores Associados, 2010.

Da nova LDB ao novo plano nacional de educação: por uma outra política educacional. Campinas, SP:

Autores Associados, 2002. 
SOUZA, Celina. Políticas públicas: uma revisão da literatura. Sociologias, Porto Alegre, ano 8, n. 16, p. 20-45, jul./dez. 2006.

TEIXEIRA, M. C. A. Políticas públicas para pessoas com deficiência no Brasil. 2010. 131f. Dissertação (Mestrado em Administração de Empresas) - Programa de Pós-graduação em Administração de Empresas da Fundação Getúlio Vargas, São Paulo, 2010.

TRÓPIA, Patrícia Vieira. O Plano Nacional de Educação em disputa no governo Lula. Revista de Educação PUC-Campinas, Campinas, SP, v. 16, n. 1, jan./jun. 2011.

Recebido: $13 / 10 / 2017$

Aprovado: 18/11/2017 